Article

\title{
Migration as a Capability: Discussing Sen's Capability Approach in the Context of International Migration
}

\author{
Marta Eichsteller \\ School of Sociology, University College Dublin, Dublin, D04, Ireland; E-Mail: marta.eichsteller@ucd.ie \\ Submitted: 15 August 2020 | Accepted: 12 October 2020 | Published: 18 February 2021
}

\begin{abstract}
Migration is a form of spatial and social transplant from one local and national context to another. Migration trajectories often expose the underlying intersections of social relations and social hierarchies that underpin cultural and social national environments. Migrants who encounter those complex structural inequalities must learn to negotiate classed, gendered and racialised social relations and seek the most suitable social positions within new systems. This article builds on Amartya Sen's capability approach to conceptualise migrants' embeddedness in the framework of social inequalities and explores the relationship between individual choices, resources and entitlements. It points towards patterns of advantage and disadvantage that frame migrants' opportunities and draws tacit analytical, theoretical and methodological links that have the innovative potential for the study of migration. Building on the parallels between studies in the fields of social inequalities and migration, this article argues that Sen's analytical and conceptual approach provides innovative insights into migration experiences, and Sen's unique reasoning opens up new avenues for the discussion of migrants' social justice.
\end{abstract}

\section{Keywords}

capabilities; choice; entitlement; inequalities; migration; social justice

\section{Issue}

This article is part of the issue "Migration and Unequal Social Positions in a Transnational Perspective" edited by Thomas Faist (Bielefeld University, Germany).

(C) 2021 by the author; licensee Cogitatio (Lisbon, Portugal). This article is licensed under a Creative Commons Attribution 4.0 International License (CC BY).

\section{Introduction}

There is little doubt that the global world-interconnected, fluid and dynamic-has a substantial impact on individual lives. The processes and shifts occurring at different levels of the global economy, politics and culture are transforming social structures, creating new circumstances that encourage individuals to take risks in the search for a better future. Transnational mobility is one of these opportunities, but it comes with the complexity of individual and social challenges that alter biographical trajectories and national histories alike. Migration studies operate in the unique theoretical and methodological environments that aim to capture the individual experiences of migration as well as the international and intercultural social relations within global, national and local scale. Migration studies regularly tap into the underlying disproportion of status and individu- al rights on the one hand, and the structural patterns of the global economy and international politics on the other. This complex and diverse field of study incorporates a wide array of theoretical and methodological approaches focusing broadly on issues of movement, settlement and control embedded in the context of citizenship (Collyer \& King, 2015; Kivisto \& Faist, 2009). However, it is becoming increasingly difficult to ignore the fact that migration studies rarely engage with the discourse of social justice, such as ideas of fairness and representation, despite them forming a vital part of migrants' experience.

This article explores the potential of Amartya Sen's "capability approach" that proposes the social justice system that focuses on a person's ability to act and choose, rather than resources and utility-based justice systems that highlight the importance of individual resources and needs. The focus on capabilities addresses two crucial shortcomings of other inequality approaches: It does 
not assume that everyone has the same needs, and it highlights the systemic obstacles that frame a person's agency, such as discrimination (Burchardt \& Hick, 2016). The capability approach points towards 'the central relevance of inequality of capabilities in the assessment of social disparities' (Sen, 2010, p. 232), which aligns closely with the everyday experiences of migrants all over the world. These parallels between studies in the fields of social inequalities and migration suggest that Sen's analytical and conceptual approach can provide innovative insights into studies of migration. Furthermore, Sen's unique conceptualisation of fairness building on capabilities opens up new avenues in the discussion of social justice for migrants.

Sen's theoretical framework and migrations studies have interacted to some extent via the field of development studies. Sen's ideas formed the cornerstone of the "human development paradigm" (Nussbaum, 2011) focused on the questions of how people can act and what opportunities they may have to do so. Within this paradigm, migrant workers are perceived as effective "agents of development" (Nussbaum, 2011). Their contribution to national economies and developmental potential of remittances have been identified as a leading force in economic development. At the same time, there has been some recognition of the personal costs, associated with the loss of social and economic rights, highlighted by the Global Forum for Migration and Development in 2010 on shared prosperity, shared responsibility (Juran, 2016). According to Preibisch, Dodd, and Su (2016, p. 2113) 'both the capabilities and development approaches are used to emphasise the agency and potential of migrants to contribute to their economic growth and poverty alleviation in addition to that of their families, communities and countries of origin.' I argue, however, that this evolution of the capability approach within the context of development studies does not do Sen's capability approach justice. Sen (2010) argues that his approach should be focused on the inequalities and assessment of social disparities, that concentrating on capabilities is not a specific formula for policy decisions, nor is the way to evaluate policy frameworks, such as Human Rights agendas. This article expands on Sen's (2010, p. 232) argument that the capability approach can be used to its greatest advantage to inform the 'assessment of societies and social institutions' and draw attention to the decisions that would have to be made to address the issues of fairness and social justice. This approach applied to migration research deepens our understanding of migration and introduces new analytical tools for international research agendas.

The first section of this article discusses thematic links between migration studies and Sen's approach to social inequalities. This section highlights the importance of the life quality discourse, the lack of migrant representation in the social justice discourse and the importance of freedom of choice. The second section outlines the analytical value of Sen's capability approach, partic- ularly the distinction between capability as an ability to act and functioning understood as the outcome of this action, the focus on entitlement as a structural obstacle for capabilities and the relation between capability sets and structural advantage and disadvantage. The discussion section highlights the implications of the capability approach for the development of social justice theory in the context of migration as well as the theoretical and methodological developments that have the potential to enrich both academic fields.

\section{Social Inequality Implications in the Context of Migration Studies}

In the context of the ongoing theoretical and methodological developments in migration studies, transnational social practices often overlap thematically and analytically with the complex landscape of social inequalities (Faist, 2018). As groups and individuals, migrants exist in the liminal spaces within social structures, where the unequal distribution of wealth and privilege determines their life chances and life choices over their lifetime. Migration research exposes the underlying power dynamics within and between societies as well as develop new relations of advantage and disadvantage. To address this nexus of migration and social inequalities, this article forges analytical and thematic links between the "capability approach" based on Amartya Sen's original work on inequalities and key aspects of transnational practices that aim to answer the question on the value of choices, lack of representation and the idea of "quality life."

Having been awarded the Nobel Memorial Prize in the field of economics in 1998, Amartya Kumar Sen is one of the leading contemporary intellectuals. $\mathrm{He}$ is a critical economic, social and political theorist with interests in social choice theory, welfare economy and international development studies. According to Hamilton (2019, p. 1):

His capabilities approach changed the way we think about human agency, the standard of living, justice and democracy and shake to the very foundations many of theoretical edifices we have constructed around how best to conceive of our lives together.

In the context of migration studies, Sen's work on social disadvantage is potentially powerful. Sen champions a theory of justice based on fairness that 'must be deeply and directly concerned with the actual freedoms enjoyed by different persons-persons with possibly divergent objectives - to lead different lives that they can have reason to value' (Sen, 1990b, p. 112). This conceptualisation strikes a chord in the context of migration and exposes three areas of overlap between the relatively unequal, structural positioning of migrants and their individual capitals and aspirations in the pursuit of a better life: the notion of life quality, the lack of representation in the public debate and the importance of individual choice. 
The first overlap between Sen's theory of justice and migration highlights the issue of quality of life, defined not merely as survival or the fulfilment of basic needs, but 'in terms of valued activities and capability to achieve these activities' (Sen, 1990a, p. 43). This point comes from Sen's critique of commodity-based justice systems that do not take account of the interpersonal variation of the ability to convert primary goods into a meaningful quality of life. The idea of the quality of life comes from Adam Smith's assessment that, to fully participate in social activities, individuals need to be able to fit in with others without a feeling of shame. According to Sen, to conceptualise social inequalities is to understand that there cannot be a single indicator for measuring the quality of life and that any such measurement needs to reflect the environment in which the individual exists and their individual choices. In the context of migration, the quality of life will be measured against the expectations of multiple reference groups, including the receiving and sending communities as well as the migrant groups themselves, with an added value attached to individual choices. This liminal position of migrants in relation to multiple points of reference allows them to build their individual notion of quality of life that stands against the set measures of value. This is the case, for example, in the situation when migrants are perceived as working below their potential or qualification, but they accumulate their value by accumulating financial resources that can be converted according to their definition of quality of life in their home country. To understand the inequalities in the context of migration, we need to identify what activities constitute value and how it is achieved.

The second juncture between social inequalities and migration focuses on the lack of power that leads to a lack of representation and voice in the political, social and cultural decisions that frame migrants' experiences directly. Sen (1990a, p. 45) argues that 'smugness about continued deprivation and vulnerability is often made to look justified on the grounds of a lack of strong public demand and forcefully expressed desire for removing these impediments.' This relatively powerless status of individual migrants and their communities is rooted in the utilitarian nature of these types of systems. Sen critiques this utility-based justice system because it forces people who form the relative minority to adjust their perceived value and quality of life to align with the majority's expectations embedded in the migrant status. Sen (1990a, p. 45) argues that:

A thoroughly deprived person leading a very reduced life might not appear to be worse off in terms of the mental metric of utility if the hardship is accepted with non-grumbling resignation. In situations of longstanding deprivation, the victims do not go on weeping all the time and very often make great efforts to take pleasure in small mercies and to cut down personal desires to modest "realistic" proportions.
Research on migration often takes these statements of utility as an acceptance of the status quo, often assigning judgements to the inability of migrant communities to exert pressure and make their voices heard.

The third overlap between the field of migration and Sen's approach to inequalities is the focus on freedom of choice that should be independent of the notion of achievement. Here, in particular, Sen stresses that the quality of life is not based on what we can achieve with the same amount of resources, but the freedom to choose how people would like to live their lives. In this context, migration itself may be a choice that leads to individually defined economic or social achievements. But it can also be the outcome of a lack of any other choices, as is the case for people fleeing conflict or prosecution, where the achieved status of refugee or asylum seeker does not convert individual resources into actual freedom. Sen (2010) stresses that the main goals of a capabilities-based justice system are to focus on systemic opportunities and freedom of choice, rather than simply the number of individual resources or a migrant's utility. This focus can be applied to great advantage in the field of migration studies.

Sen's original idea of a capabilities-based justice inspires analytical and theoretical innovation that can be applied in the field of international migration. In particular, Sen's early work on the capability approach can be adopted as an analytical framework for understanding the social structures that frame migrants' movement opportunities as well as their social and political rights. For the purpose of this article, I have selected three main aspects of the capability approach that carry particular potential and relevance for migration studies, namely the conceptual dichotomy between capabilities and functionings, the relations between resources and entitlements, and Sen's commentaries on the role of the state.

\section{The Analytical Links between the Capability Approach and Migration Studies}

The capability approach is at the centre of Sen's conceptual framework and forms the philosophical cornerstone of his later theory of justice and theory of social choice. In essence, it focuses on 'the capability to function' (Sen, 1990a, p. 43) as the main aspect determining an individual's positioning in the framework of social inequalities. Individuals with more opportunities to act will have a more advantageous position within the social system, and these with fewer opportunities will be in the position of disadvantage. Sen (1990a, p. 50) argues that 'the capability approach can, thus, be used at various levels of sophistication, and how far we can go would depend on the practical consideration of what data we can get and what we cannot.' Framing the analysis of migration within the capability approach framework offers new analytical lenses that can accommodate a wide range of empirical research methodologies equipped to pick up the elements of individual choice 
and wider social change, including cognitive, narrative and biographical methodologies.

\subsection{Analysis of Capabilities and Functionings}

Within Sen's theoretical landscape, the term capability refers to the "potential" to freely pursue multiple opportunities and is related to the functioning that is the current state of being. Each individual has a set of capabilities, some of which will be converted into actual functionings whilst others will be abandoned. This introduces an element of retrospection into research designs that investigate the capabilities set before the actual functioning has happened. At each stage of life, an individual's capability set is changing depending on the conditions in which individuals find themselves. According to Sen, individuals with more capabilities have a relatively more advantageous position in society than those with limited capability sets. Advantage and disadvantage are rooted in 'the person's freedom to lead one type of life or another; that is, it reflects the person's ability (that includes her living conditions) to choose from possible lives' (Hamilton, 2019, p. 55).

In this context, we can consider migration in both meanings, either as a capability set or as functioning with its own set of opportunities to choose from. Migration, as part of a capability set, should be considered as one out of the range of opportunities. The analysis of other opportunities and the reasoning behind the choice to migrate adds to the analysis of the structural advantage in the analysis of migration movement. For example, in Eichsteller (2017), three styles of voluntary migration narratives are recognized to capture the selfpositioning of the migrant within the broader social structures. The narrative of "explorer" is expressed as a lifeproject pursued by an individual migrant, and each step, including migration episodes, counts as a personal experience that forms part of the personal journey. This type of narrative would indicate multiple choices and access to opportunities that can be seen through the lenses of advantage. By contrast, the narrative of "guest" indicates a limited capability set. It focuses on the limited opportunities, lack of social status and sense of disadvantage in social relations. Eichsteller (2017) also points towards the narrative type of the "trader," who uses institutional frameworks, such as international companies or educational institutions, to facilitate opportunities and broker the professional skills for the sense of belonging and successful convert capability into functioning. All these narrative types orient the analytical framework towards the capability sets that determine not only access to resources and the individual perception of a person's utility but also the structures of advantage and disadvantage.

The expressions of choice and opportunities are often embedded in the language and narrative form used to describe the experience. Sen (1990a) uses the analogy of "fasting" and "starving" to highlight the difference between the same type of condition with a completely different set of capabilities. In each case, the more choices and opportunities are available to an individual, the more privileged their position is in the social structures. Therefore, a significant advantage of the capability approach lies in its focus on opportunities rather than resources. Migration studies, especially those focused on individual agency, are largely concerned with the power of individual resources. They stress the relevance of economic means in facilitating migration movements and subsequent settlement and social capital as the ability to engage with new social networks, thus attributing the responsibility for the migration outcome largely to the individual. This supports the idea that, by merely making resources available for individual migrants, for instance in the form of housing or employment in lowskilled jobs, they can be converted into successful assimilation or at least adaptation story. Within the capability approach, this way of thinking does not hold. According to Burchardt and Hick (2016), the capability approach recognises that, firstly, people have different needs that cannot be fulfilled by a one-size-fits-all approach and, secondly, that migrants may face systemic obstacles, such as discrimination, that may significantly limit their capability set and put them at a disadvantaged position.

\subsection{Focus on Resources and Entitlements}

The capability approach focuses on opportunities that create an advantage. Along with the ability to choose, Sen (1983a) points to the notion of entitlement that highlights how individuals acquire capabilities. According to Sen (1983a, p. 754), 'entitlement refers to the set of alternative commodity bundles that a person can command in a society using the totality of rights and opportunities that he or she faces.' In Sen's work, an individual's entitlement is comprised of two elements: a person's resources (endowment) that can be bought and exchange possibilities (exchange entitlement) that are determined by their status and rights. Sen highlights that the main commodity that a person can sell his labour, and for that reason, a person's entitlement primarily depends on the ability to find a job. But entitlement is more than a simple income measure. According to Sen (1983a, p. 755), entitlement is concerned with what people can and cannot do and therefore should be conceptualised to capture the complexity of entitlement relations, such as access to and affordability of health provisions, education, social equality, self-respect and freedom from harassment.

In the context of migration, the endowment can include economic resources as a start, but in the long term, it is more about any valuable assets that can be exchanged in the new structural context, mostly to secure a place in the labour market, but also to gain access to other resources, such as information. For migrants, these assets would include physical health, the ability to communicate, transferable skills, an education degree, as well as other skills, such as creativity, adaptability, 
resourcefulness and trustworthiness. To illustrate the complexity of the exchange and entitlement, we can look at the study by Davis, Day, Eichsteller, and Baker (2017) that analyses the biographical experiences of migrants learning a second language. It questions the assumption that the ability to speak the language will help with the individual's integration into their new social structures, namely assist in finding jobs and facilitate access to a broader set of opportunities. The study findings suggest instead that simply learning a second language (building an endowment) does not necessarily achieve this goal. The authors explain this by drawing on Bourdieu's notion that, to become fluent in a second language, the person needs to be in a situation when he or she has the right to speak and right to be heard. This notion of "right" would link directly with the exchange entitlement. The person can learn a new language but then needs to be in a position to use it. Among migrants, including refugees, illegal migrants and asylum seekers, this entitlement is often missing and therefore hinders the language acquisition and possible integration.

Exchange entitlement is the aspect of the capabilities approach that carries particular promise for the field of migration studies. It taps into the element of migrant stories that often include the word "luck" to explain successful migration pathways. Exchange entitlement makes it possible to exchange endowments into successful functioning. It highlights that 'the freedom of agency that we individually have is inescapably qualified and constrained by the social, political and economic opportunities that are available to us' (Sen, 2000, pp. xi-xii). This element of Sen's theoretical framework currently takes on a new shape within development studies (Nambiar, 2013) investigating the institutional entanglements and constraints that directly affect the conversion of individual skills and resources into actual opportunities.

\subsection{Expanding Individual Capabilities and Development}

The last element of Sen's capability approach introduced here with unique relevance to migration studies is his understanding of the role of the state and community as an enabler for the improvement of quality of life. Sen builds on Marx in arguing that the exact role of the state and corresponding social structures should be about 'replacing domination of circumstances and chance over individuals by the domination of the individuals over chance and circumstance' (Sen, 1983a, p. 754). The focus of the state should be on understanding the entitlement on the one hand and expanding the capabilities set on the other. In the context of migration studies, the focus on creating opportunities that enable the individual agent to tackle complex circumstances produces a better social, economic and political outcome than simply providing short-term resources based on an external assessment of individual needs. Within the context of migration studies, social policies should focus on building institutional support that enables individual agents, both citizens and non-citizens, to successfully convert individual endowments into functionings by recognising the role of exchange entitlements and the importance of individual choice.

The focus of migration research incorporating a capability approach would highlight the structural features of social relationships that are made on the basis of this entitlement. Sen (1983a, p. 755) argues that 'a person can acquire some capabilities, i.e., the ability to do this or that and fail to acquire some other capabilities. The process of economic development can be seen as a process of expanding the capabilities of people.' Analysis of changing capabilities, between countries as well as within a country's historical context, can enrich a comparative understanding of social entitlements in the context of migration. This research agenda can be applied to different structural levels (Nambiar, 2013), including regulations and legal frameworks, social relations and personal factors.

\subsubsection{Capabilities in the Context of Legal Frameworks}

Analysis of capabilities associated with regulatory legal frameworks should focus on access to legal infrastructure as well as the institutions associated with law enforcement. In the context of migration studies, the legal regulation of mobility at national and international level creates a multi-tiered system of advantage and disadvantage, posing varied levels of restrictions for citizens of other countries, ranging from unrestricted movement, exclusive visa systems, to refugee and asylum-seeker requirements. From an individual migrant's point of view, these legal regulations are often reinforced by bureaucratic administrative infrastructure that may significantly reduce their capabilities. Application procedures for a tax number, social insurance, welfare benefits and qualification recognition can set up road-blocks to the individual's exchange entitlements. One of the most infamous cases of these administrative practices is the creation of a "hostile environment" promoted by the UK's Home Office in 2012 under Theresa May, which encouraged civil servants to be overzealous in their practices in order to make the legal stay and work in the country as difficult as possible. The capability approach analysis in this context can highlight administrative practices that are affecting individuals' opportunities. In some contexts, they are designed to drain individual resources and delay the ability to exchange them. These practices may take the form of repeated delays, such as ongoing demands for documents, or high administrative costs. By contrast, analysis of successful transfers of entitlements would highlight the social processes that open up opportunities and expand the capabilities set.

\subsubsection{Capabilities and Social Change}

The analysis capabilities associated with social factors should explore the intersectionality of power positions 
determined by gender, ethnicity, age and social class that constrains migrants' opportunities and entitlements. In his writings, Sen (1990b, 1999, 2000) highlights particularly the role of gender in restricting capability sets due to biological and social factors, but the minority-majority hierarchies embedded in the ethnicity relations, as well as a social class, are equally relevant for the analysis of structural disadvantage. With the conceptual framework of the capability approach, migration research should aim to capture the structural power relations and gain insight into the creation and change in the discrimination patterns within as well as between states. This geographical mapping of social capability patterns holds the significant analytical potential for migration studies.

\subsubsection{Personal Factors}

Finally, the study of individual strategies aimed at converting individual resources and entitlements into capabilities can be particularly relevant for migration studies. This approach holds an additional advantage when contrasting individuals who experience lifelong disadvantage within the social structure with those who enter it from the outside. Analysis of personal factors should include issues of access to institutional frameworks that support an individual's well-being, including health care assistance, social welfare as well as the ability to engage and thrive in the labour market. It can also capture the process by which individual migrants either gain or lose access to a wider array of capabilities to obtain a clearer picture of broader social change.

\section{Discussion}

Drawing analytical links and tracing the parallels between discourses of migration and social inequalities brings out the potential for new theoretical and methodological innovations. Firstly, the application of the capability approach into empirical research has the potential to engage in migration research with discourses of social justice. This conversation has mutual benefits by expanding the discourse on the conceptualisation of migrants' social rights on the one hand and introducing the discourse of methodological transnationalism (Amelina \& Faist, 2012; Glick Schiller, 2007) to social justice discourse that is still framed within the national discourse. Thus far, the idea of migrants' justice has been drawing on the Human Rights agenda rather than more welfare-orientated debates. The Human Rights framing of the migration has narrowed the discussion of migrants' experiences and well-being to the issues of regulating the international movement of people (Kivisto \& Faist, 2009; Ypi, 2008). According to Ypi (2008, p. 392), justice in migration with its asymmetry between rights of immigrants versus rights of emigrants 'points to a serious moral deficiency in the theory and is incompatible with the general principle of justice.' This approach is why migration studies stay away from the social jus- tice discourse, as to claim universal rights of non-citizen individuals interferes ideologically with the politics of nation-states and privilege of citizenship.

Sen's conceptualisation to social justice does not engage with the idea of rights, but with fairness that is relative to the particular community and specific country. Sen (2010, p. 8) argues that 'in contrast with most modern theories of justice, which concentrate on the "just society"...[his work] investigates realisation-based comparisons that focus on the advancement or retreat of justice.' Sen argues that it is possible to have plural ideas and competing reasons for justice, but the real question is how we can gradually advance the fairness of social systems, rather than focus on what the ideal social system should be. In the context of migration, this conceptualisation of justice has enormous potential. It frames the discourse of justice as a notion of collective achievement-moral as well as developmentaland places the discourse of migration within the more positive context of common goals and progress, whilst characterising a possible retreat of justice as a failure to meet our own norms and common expectations, whatever they might be.

Secondly, the focus on the change in the set of capabilities combined with the idea that expanding these capabilities should form a part of social policy agenda highlights a new aspect of the dichotomy between individual agency and social structure. Most of the contemporary migration methodologies struggle to reconcile the singular character of migration experience and structural patterns that are very limited in their explanatory power. This is due to the fact that migration research focuses on the migrant's functionings, focusing on either the individual resources, often framed in terms of Bourdieu's notion of capital (Bourdieu, 1986; Erel, 2010), or broadly defined utility and needs (Apitzsch \& Kontos, 2008; Chamberlayne, Rustin, \& Wengraf, 2002). Sen's (2010, p. 18) work on justice is relevant to migration studies, as it 'cannot be indifferent to the lives that people can actually live.' It acknowledges the diversity of human experience because it places individual choice at the centre of the migration analysis. The outcomes of these choices, including the achieved functionings as well as the idea of the quality of life, the sense of agency and responsibility associated with these choices, and the structural constraints associated with entitlements, are determined by the individual's freedom of choice. This has substantial implications for the analytical frameworks and theoretical discussions of contemporary migration research and impact on a global scale.

Finally, linking Sen's capability approach with studies of transnational migration promises interesting analytical developments as to the nature of retrospective and narrative types of data that should gain importance for methodological approaches in this field. Sen is aware that methodologies and data play a key role in the application of the capability approach and argues that the selection of migrant functionings and migrant capabili- 
ties should focus on 'underlying social concerns and values' (Sen, 1990a, p. 49). But to fully capture the changes in capability sets and their impact on individual functioning, researchers need to look deeper into what Lahire $(2019$, p. 379$)$ refers to as sociological biography, 'the successive or parallel socialising experiences through which the respondent has been constituted and which have settled in them in the form of schemes or dispositions to believe, see, feel and act.' The focus on the sociological aspects of the biographical process provides a good methodological fit between migration research, the capability approach and the wider theory of social justice focused on changes in the fairness of opportunities that can be applied in a local, national and global context.

\section{Conclusion}

Sen's capability approach has been widely discussed in the fields of international development and social policy. In the ongoing debate with Nussbaum (2011) and Robeyns (2005), there has been an urgency to develop a more analytical "capabilities list" that would elaborate on the measurable aspects of inequalities and allow more comprehensive comparative frameworks. Sen's original ideas, however, inspire analytical innovation that can be applied across different academic disciplines, including international migration. This article discusses thematic parallels between the main problems experienced in the study of social inequalities and migration studies. These include the internal and external variations in perception of "quality of life" and "valued activities," judgments on the lack of voice and representation in the public discourse as well as the lack of recognition that limited choices and opportunities are the indicators of social deprivation.

By introducing Sen's analytical and conceptual approach, this article provided an overview of his unique perspective and analytical toolkit posed by the capability approach, which offers innovative insights for the field of migration studies. It explored the power relations that frame access to opportunities and tied these up with the idea of individual choice. It also conceptualised entitlement as a main structural obstacle in the individual's ability to convert their resources, such as education and skills, into whichever prosperous and fulfilling life the individual chooses to pursue. The analysis of entitlement can point towards the frameworks of structural discrimination. Furthermore, Sen's approach frames the study of advantage and disadvantage in the model of expansion and retraction of individual capabilities over time, highlighting the processes of broader social change that affect migrants and offering interesting methodological perspectives for migration research.

In addition, Sen's unique approach opens up new avenues in discussing social justice based on the idea of fairness rather than the notion of universal and highly contested rights. Sen has proposed a flexible, context- related, capabilities-based justice system that aims for the constant improvement of social relations, rather than an ideal, one-size-fits-all concept of a just society. Within this system of relations, he highlights the importance of both individual responsibilities associated with choices made and the responsibility of states and communities to gradually expand the set of capabilities in an effort of self-improvement. This potential to frame migration experiences and migration relations within a framework of social justice is a powerful incentive to explore, apply and adjust Sen's capability approach in the field of migration.

\section{Acknowledgments}

I wish to thank my mentor, Prof. Howard Davis from Bangor University, for his support and valuable comments and Vidya Diwakar from the Chronic Poverty Advisory Network for pushing me into new theoretical waters.

\section{Conflict of Interests}

The author declares no conflict of interests.

\section{References}

Amelina, A., \& Faist, T. (2012). De-naturalizing the national in research methodologies: Key concepts of transnational studies in migration. Ethnic and Racial Studies, 35(10), 1707-1724.

Apitzsch, U., \& Kontos, M. (2008). Self-employment activities of women and minorities. Berlin: Springer Fachmedien.

Bourdieu, P. (1986). The forms of capital. In M. Granovetter \& R. Swedberg (Eds.), The sociology of economic life (pp. 81-93). New York, NY: Routledge.

Burchardt, T., \& Hick, R. (2016). The capability approach to advantage and disadvantage. In D. Hartley \& L. Platt (Eds.), Social advantage and disadvantage (pp. 25-41). Oxford: Oxford University Press.

Chamberlayne, P., Rustin, M., \& Wengraf, T. (2002). Biography and social exclusion in Europe: Experiences and life journeys. London: Policy Press.

Collyer, M., \& King, R. (2015). Producing transnational space: International migration and the extraterritorial reach of state power. Progress in Human Geography, 39(2), 185-204.

Davis, H., Day, G., Eichsteller, M., \& Baker, S. (2017). Language in autobiographical narratives: Motivation, capital and transnational imaginations. Language, Discourse \& Society, 5, 1-18.

Eichsteller, M. (2017). Guest, trader or explorer: Biographical perspectives on the experiences of crossborder mobility in Europe. Ethnic and Racial Studies, 41(5).

Erel, U. (2010). Migrating cultural capital: Bourdieu in migration studies. Sociology, 44(4), 642-660. 
Faist, T. (2018). The transnationalized social question: Migration and the politics of social inequalities in the twenty-first century. Oxford: Oxford University Press.

Glick Schiller, N. (2007). Beyond the nation state and its units of analysis: Towards a new research agenda for migration studies. In Concepts and methods in migration research: Conference reader (pp. 39-72). Bielefeld: Bielefeld University.

Hamilton, L. (2019). Amartya Sen. London: John Wiley \& Sons.

Juran, S. (2016). International migration seen through the lens of Amartya Sen's capability approach. Migration Policy Practice, VI(2), 24-27.

Kivisto, P. J., \& Faist, T. (2009). Beyond a border: The causes and consequences of contemporary immigration (Sociology for a New Century Series). London: SAGE Publications.

Lahire, B. (2019). Sociological biography and socialisation process: A dispositionalist-contextualist conception. Contemporary Social Science, 14(3/4), 379-393.

Nambiar, S. (2013). Capabilities, conversion factors and institutions. Progress in Development Studies, 13(3), 221-230.

Nussbaum, M. C. (2011). Capabilities, entitlements, rights: Supplementation and critique. Journal of Human Development and Capabilities, 12(1), 23-37.
Preibisch, K., Dodd, W., \& Su, Y. (2016). Pursuing the capabilities approach within the migrationdevelopment nexus. Journal of Ethnic and Migration Studies, 42(13), 2111-2127.

Robeyns, I. (2005). The capability approach: A theoretical survey. Journal of Human Developments, 6(1), 93-117.

Sen, A. (1983a). Development: Which way now? The Economic Journal, 93(372), 745-762.

Sen, A. (1983b). Poor, relatively speaking. Oxford Economic Papers, 35(2), 153-169.

Sen, A. (1990a). Development as capability expansion. In J. DeFilippis \& S. Saegert (Eds.), The community development reader (pp. 41-58). New York, NY: Routledge.

Sen, A. (1990b). Justice: Means versus freedoms. Philosophy \& Public Affairs, 19(2), 111-121.

Sen, A. (1999). Development as freedom. Oxford: Oxford University Press.

Sen, A. (2000). A decade of human development. Journal of Human Development, 1(1), 17-23.

Sen, A. (2010). The idea of justice. London and New York, NY: Penguin Books.

Ypi, L. (2008). Justice in migration: A closed borders utopia? Journal of Political Philosophy, 16(4), 391-418.

\section{About the Author}

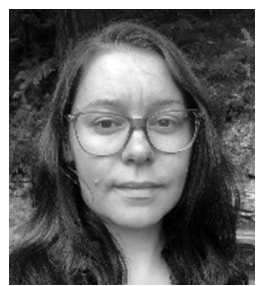

Marta Eichsteller is an Assistant Professor and AdAstra Fellow at the School of Sociology, University College Dublin. Her work is focused on biographical methodologies applied to the fields of migration and identity, social inequalities and global development. She is a strong advocate of interdisciplinary collaborations in the development of new analytical and theoretical tools. 